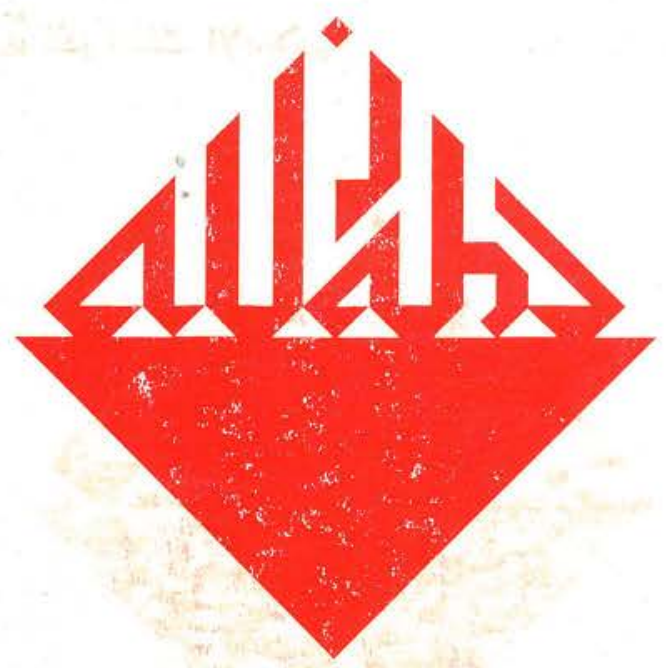

THE ULAMA IN ACEH:

A BRIEF HISTORICAL SURVEY

Yusny Saby

A SUDANESE SCHOLAR IN THE DIASPORA:

LIFE AND CAREER OF AHMAD MUHAMMAD

AL-SURKITTÎ IN INDONESIA (1911-1943)

Ahmed Ibrahim Abushouk

THE MEANING INTERPRETED:

THE CONCEPT OF BARAKAH IN ZIARAH

Jamhari 


\section{STIDLA ISLAIIIKK}

Indonesian Journal for Islamic Studies

Vol. 8, no. 1,2001

EDITORIAL BOARD:

M. Quraish Shihab (IAIN Jakarta)

Taufik Abdullah (LIPI Jakarta)

Nur A. Fadhil Lubis (IAIN Sumatra Utara)

M.C. Ricklefs (Melbourne University)

Martin van Bruinessen (Utrecht University)

John R. Bowen (Washington University, St. Louis)

M. Atho Mudzhar (IAIN Yogyakarta)

M. Kamal Hasan (International Islamic University, Kuala Lumpur)

EDITOR-IN-CHIEF

Azyumardi Azra

\section{EDITORS}

Johan H. Meuleman

Jajat Burhanuddin

Fuad Jabali

Jamhari

Oman Fathurahman

\section{ASSISTANT TO THE EDITORS}

Heni Nuroni

ENGLISH LANGUAGE ADVISOR

Richard G. Kraince

ARABIC LANGUAGE ADVISORS

Nursamad

\section{COVER DESIGNER}

\section{S. Prinka}

STUDIA ISLAMIKA (ISSN 0215-0492) is a journal published quarterly by the Center for the Study of Islam and Society (PPIM), IAIN Syarif Hidayatullah, Jakarta (STT DEPPEN No. 129/SK/DITJEN/PPG/STT/1976) and sponsored by the Department of Religious Affairs of the Republic of Indonesia. It specializes in Indonesian Islamic studies, and is intended to communicate original researches and current issues on the subject. This journal warmly welcomes contributions from scholars of related disciplines.

All articles published do not necessarily represent the views of the journal, or other institutions to which it is affiliated. They are solely the views of the authors. The articles contained in this journal have been refereed by the Board of Editors.

STUDIA ISLAMIKA has been accredited by The Ministry of National Education, Republic of Indonesia as an academic journal. 


\title{
Transformasi Sistem Pendidikan Islam: Pergulatan Identitas Muslim Melayu-Patani
}

\author{
Hasan Madmarn, The Pondok and Madrasab in Patani, \\ Bangi: Penerbit Universiti Kebangsaan Malaysia, 1999, 143 halaman
}

Abstract: The book attempts to explain the dynamics of the Islamic education system in Patani, Thailand, from its beginning up to the time when the Malay world, to which Patani belongs, was modernized. A compari. son of Islamic education in Patani, with that which exists in other areas such as Indonesia and Malaysia, is complicated, but this is the very reason why it is so interesting.

In the context of education, Islam-including the Islam developed in Malay-Patani areas-has played a significant, even a dominant, role. It is the driving force bebind the establishment, the development, and the enforcement of educational institutions. Here pondok, pesantren, meunasah, surau and other traditional institutions of education must be mentioned for-in the Malay-Nusantara context-they have been instrumental in the whole intellectual renaissance in the region. Rich Islamic traditions were studied and socialized intensively in those institutions and this, in turn, enabled the local ulamas to produce important works in the field of Islamic studies.

For periods, those traditional institutions were deeply rooted in the Malay-Patani Muslim community and became instrumental to defining their ethnic identity (Malay) and religion (Islam). This is unsurprising since Malay-Patani is one of the regions where Malay Muslims are a minority, who often have to struggle to protect themselves from other major. ity groups. 
The book consists of eight chapters and through those chapters three main issues are raised:

First, descriptions on the golden age of Islamic traditions in the MalayPatani region, especially on the important role of its ulamas, particularly Shaikh Daroud al-Fatani and Shaikh Abmad al-Fatani. The ulamas of the Malay-Patani, who-like other ulamas in Malay-Indonesia-had a strong network with those of the Haramayn, were able to create a good atmosphere in the Malay-Patani region in which Islamic sciences could grow, and this was initiated by establishing traditional educational institutions which, in Patani, were known as "pondok."

Second, discussions on the dilemmas of the Malay-Patani Muslim minority in maintaining their interests in their institutions of education. The government of Thailand made a policy to nationalize the education system throughout the country, including Patani. According to the policy all educational institutions, including pondok, in Thailand should adopt modern teaching-learning methodology and include subjects related to the Thai language, culture and religion, which is Budhist. To the majority of the Malay-Patani Muslims this is problematic. To adopt the government policy, in their eyes, is to put the existence of their traditional education in 'pondok' in danger. Their ethnic, cultural, and religious identity, could also be threatened by the policy. But, if they resist, there is also no guarantee that they will survive.

Third, elaboration on the efforts of the Malay-Patani Muslims to come to terms with the government policy on education in such a way that they do not confront the Thai government, which is of course unproductive, but at the same time they do not lose the values of their religion and traditions. One of the alternatives to come out from such dilemmas is to change the system of the pondok, which is deemed as out of date by the Thai government, into Madrasah with its modern education system, the curriculum of which is modeled according to the Middle Eastern Madrasahs. When the Madrasah system is in accord with modern teaching method, the next step, although not all the Madrasah do this, is to change the Madrasah into the Private Islamic Schools, in which the Thai cultural education become part of the curriculum. With all of these efforts, instead of losing their ethnic and religious identity, the Malay. Patani Muslim community gets dual benefits: on one band they are able to protect their Malay identity, and on the other hand they can learn the Thai culture. 


\section{Transformasi Sistem Pendidikan Islam: Pergulatan Identitas Muslim Melayu-Patani}

Hasan Madmarn, The Pondok and Madrasah in Patani,

Bangi: Penerbit Universiti Kebangsaan Malaysia, 1999, 143 halaman

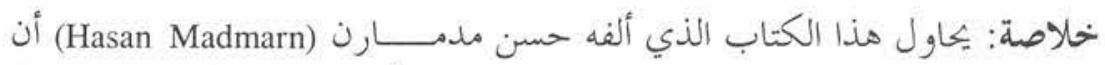

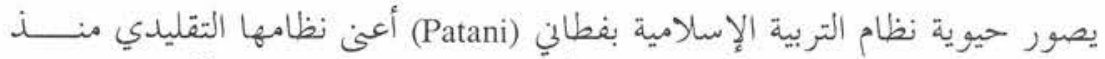

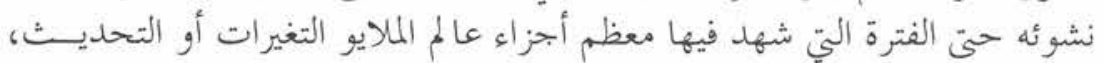

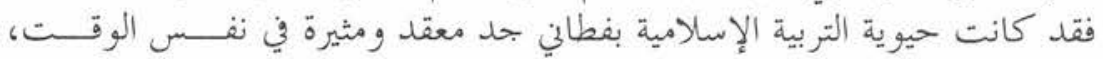

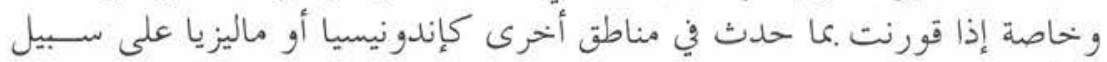

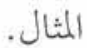

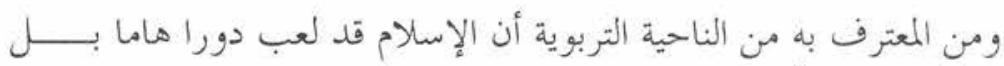

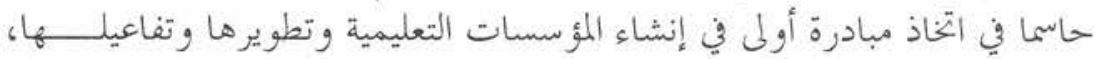

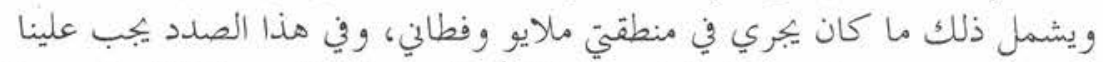

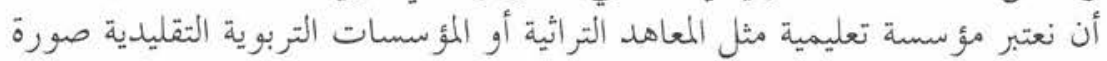

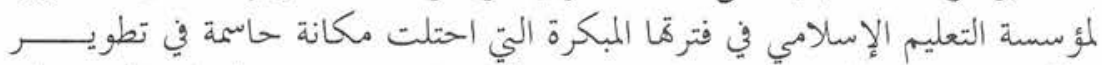

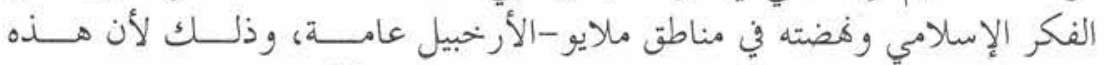

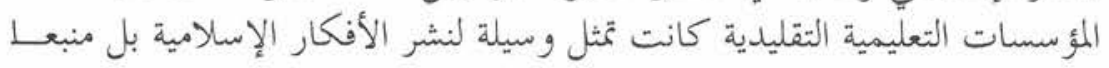

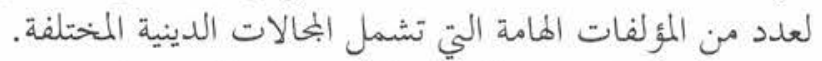

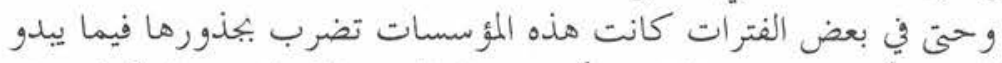

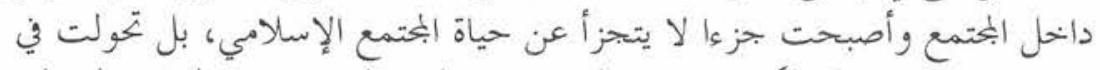

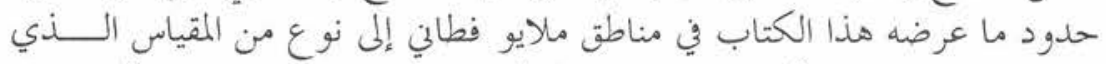

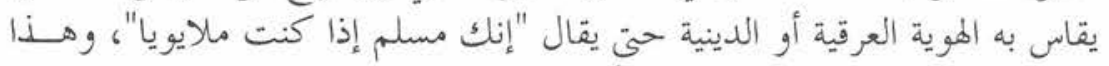

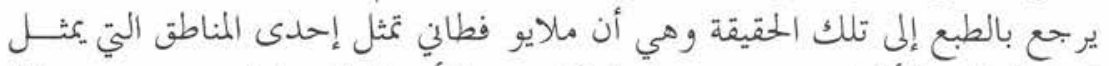

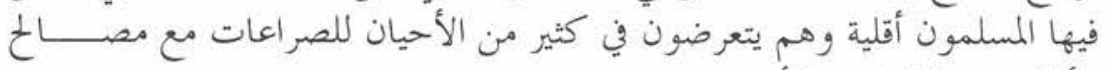

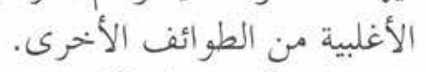

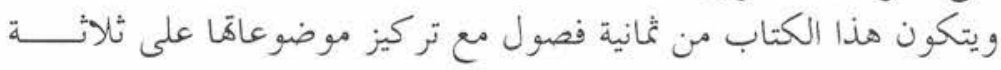




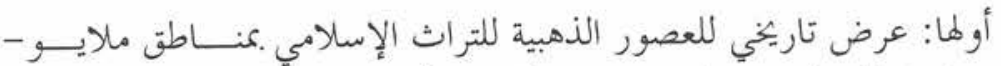

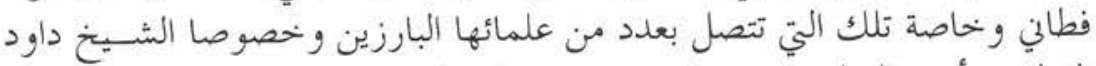

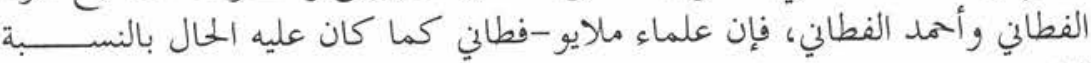

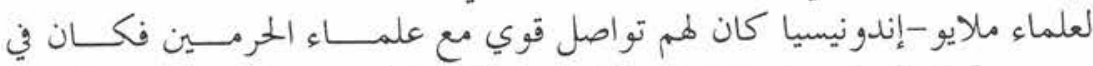

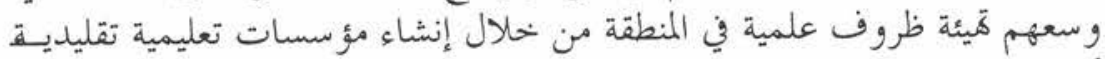
أو ما يطلق عليها في فطاني باسم فندق فئس (Pondok)؛

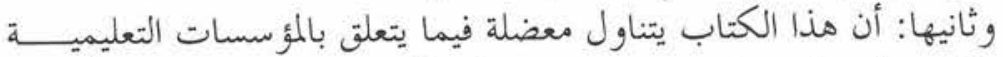

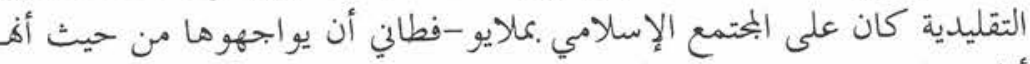

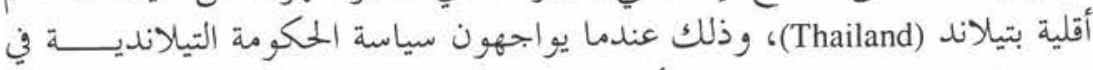

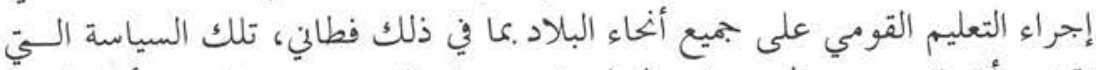

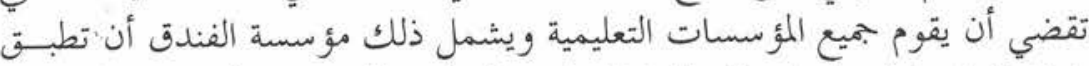

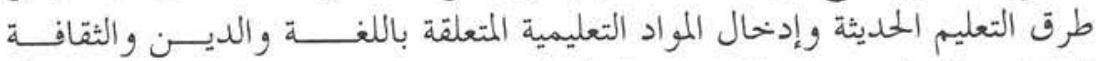

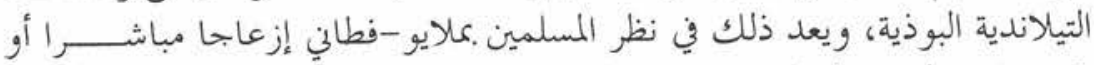

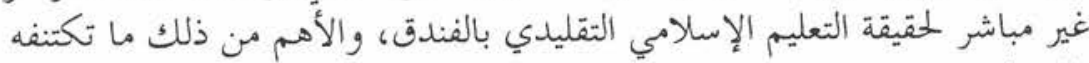

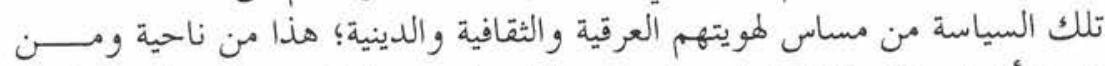

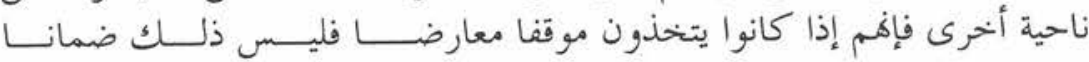

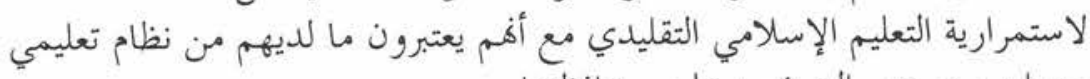
جزءا من هويتهم التي يجب عليهم التهب محافظتها.

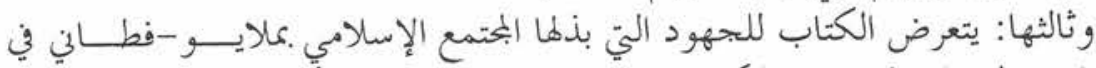

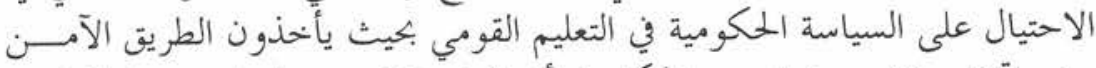

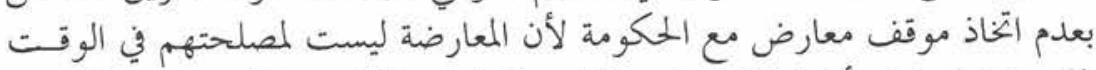

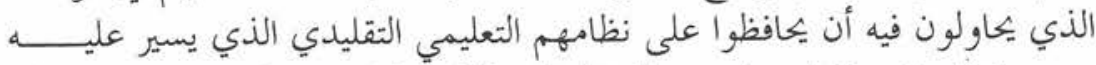

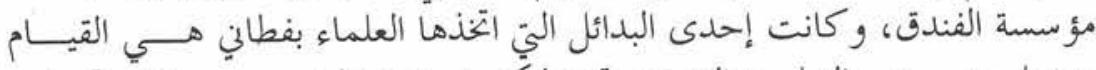

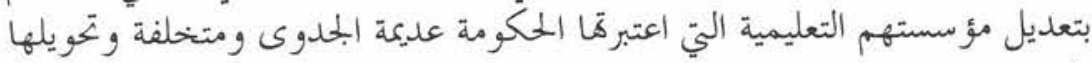

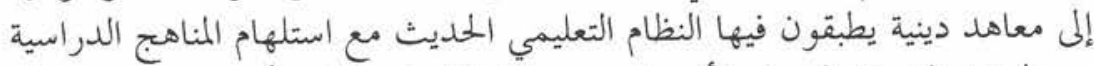

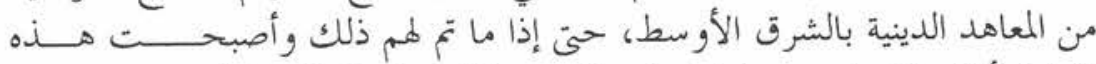

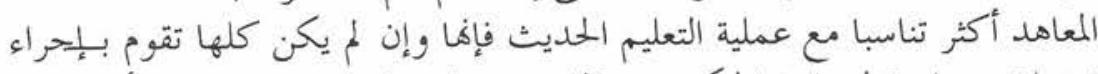

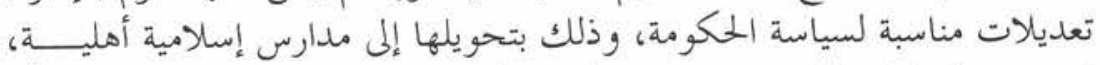

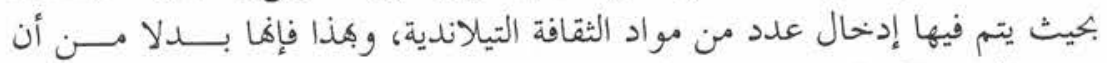

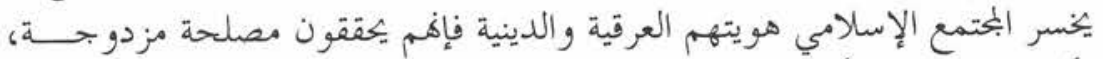

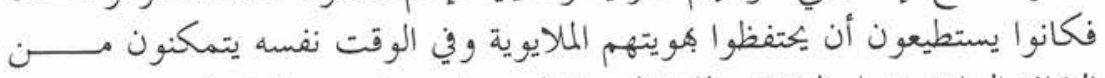

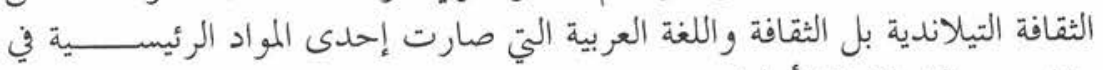
مدارسهم الإسلامية الأهلية. 
$\mathrm{D}$ alam konteks pendidikan, Islam -termasuk yang berkembang di wilayah Melayu-Nusantara- diakui telah memainkan peran yang sangat signifikan, bahkan sangat dominan, dengan mengambil posisi terdepan dalam pendirian, pengembangan, serta pemberdayaan lembaga-lembaga pendidikan. Dalam hal ini, kita harus menyebut lembaga pendidikan semacam pondok, pesantren, meunasab, surau, atau lembaga pendidikan tradisional sejenis ${ }^{1}$, sebagai bentuk lembaga pendidikan Islam periode awal yang -dalam konteks $\mathrm{Me}$ layu-Nusantara - telah menempati posisi sentral dari dinamika perkembangan dan kebangkitan intelektual Islam secara keseluruhan. Dikatakan demikian karena pada kenyataannya lembaga-lembaga pendidikan tradisional tersebut - di wilayah mana pun ia berkembangtelah berfungsi sebagai sarana untuk sosialisasi berbagai pemikiran keislaman, dan bahkan sebagai tempat lahirnya sejumlah karya penting dalam berbagai bidang keagamaan.

Di wilayah Melayu-Indonesia, pondok atau pesantren, sejak awal, dan bahkan hingga kini, telah menunjukkan vitalitasnya sebagai basis kekuatan sosial, kultural, keagamaan, dan bahkan politik, yang turut membentuk bangunan kebudayaan bangsa selanjutnya. Dalam konteks Jawa misalnya, pesantren - selain sebagai transmitter keilmuan Islam tradisional-memiliki peran sentral pada masa awal pendirian kerajaan Islam Demak, Cirebon, dan Banten di daerah pesisir utara Jawa, serta pada masa kerajaan Mataram Islam di daerah pedalamannya. Demikian halnya pada sekitar abad ke-19, pesantren menjadi basis kekuatan sosial politik masyarakat pedesaan dalam melawan penjajahan kolonial Belanda (lihat Dhofier 1994: 2; lihat juga Suryo 2000: 65). Tidak heran, jika kemudian pesantren menjadi kajian yang menarik bagi para sarjana semisal Rahardjo (1974), Geertz (1976), Steenbrink (1994), Dhofier (1994), dll.

Hingga beberapa periode, lembaga-lembaga pendidikan tradisional tersebut tampaknya memang telah mengakar kuat serta menjadi bagian yang tak terpisahkan dari masyarakat Muslimnya. Bahkan, di wilayah Melayu-Patani yang akan dibicarakan, lembaga-lembaga tersebut menjelma menjadi semacam instrumen untuk mendefinisikan identitas etnis dan agama, dalam hal ini etnis Melayu, dan agama Islam. ${ }^{2}$ $\mathrm{Hal}$ ini tentu saja terkait dengan kenyataan bahwa Melayu-Patani merupakan salah satu wilayah di mana kelompok Melayu Muslimnya merupakan kelompok minoritas, yang seringkali harus berbenturan dengan kepentingan-kepentingan kelompok di luar dirinya yang lebih besar. Mengutip teori solidaritas etnisnya Karl W. Deutch, 
umumnya sejauh kelompok-kelompok minoritas di dalam suatu negara mendapat perhatian yang proporsional, tampaknya tidak akan menimbulkan masalah sama sekali. Akan tetapi, jika mereka sudah dipandang sebagai masalah, persoalannya akan menjadi lain (lihat Deutch 1969: 159).

Dalam perkembangan berikutnya, ketika arus perubahan atau modernisasi semakin deras melanda berbagai kawasan dunia Muslim, lembaga-lembaga pendidikan tradisional tersebut dipaksa berhadapan dengan realitas modernisasi sistem pendidikan, yang dalam beberapa hal, dianggap mengancam eksistensi mereka. ${ }^{3}$ Memang, nasib lembaga-lembaga pendidikan tradisional tersebut berbeda antarsatu wilayah dengan wilayah lainnya. Sebagian lenyap tergusur oleh ekspansi sistem pendidikan modern - untuk tidak menyebut sistem pendidikan "sekuler"; tetapi sebagian lagi mengalami tranformasi menjadi, atau setidak-tidaknya menyesuaikan diri dengan, sistem pendidikan modern tersebut. ${ }^{4}$

Buku yang ditulis oleh Hasan Madmarn ini berusaha melukiskan dinamika sistem pendidikan Islam di Patani, dalam hal ini sistem pendidikan Islam tradisionalnya, sejak awal kemunculannya hingga masa di mana arus perubahan atau modernisasi melanda sebagian besar dunia Melayu, termasuk Patani. Seperti akan kita lihat, dinamika yang terjadi di Patani di satu sisi sangat rumit, tetapi di sisi lain justru menarik, apalagi jika dibandingkan dengan apa yang terjadi di wilayah lain semisal Indonesia atau Malaysia.

Patani sendiri merupakan sebuah propinsi di wilayah selatan Thailand, yang pernah menjadi salah satu pusat pendidikan Islam, dan dalam konteks dunia Muslim Melayu- bahkan pernah dijuluki sebagai "the cradle of Islam". Sebutan ini tampaknya tidak terlalu berlebihan jika melihat kenyataan bahwa sejak paruh pertama abad ke18 hingga awal abad ke-19, Patani telah melahirkan beberapa ulama mumpuni dan produktif semisal Shaikh Dâwud al-Fattânî $\hat{\jmath}^{5}$ dan Shaikh Ahmad al-Fattânî́. Di antara para ulama Melayu, Shaikh Dâwud alFattânî bahkan pernah dianggap sebagai the most productive author of Kitab Jawi in the nineteenth century (lihat Matheson \& Hooker 1988: 1). Ia telah menghasilkan sedikitnya 66 karya berbobot di berbagai bidang keislaman.?

Akan tetapi, penting dicatat bahwa Patani tentu saja bukan wilayah pertama di dunia Melayu yang menjadi pusat keilmuan Islam, karena pada awal abad ke-16 hingga akhir abad ke-17, Aceh pun telah memainkan peran yang sangat signifikan dalam perkembangan pendi- 
dikan dan pemikiran Islam di wilayah Melayu Nusantara, khususnya Indonesia, dengan tokoh-tokoh sentralnya semisal Hamzah Fansûrî, Shamsuddîn al-Sumatrânî, Nûruddîn al-Rânîrî, dan 'Abdurrauf al-Sinkîli $\hat{1}^{8}$. Karena alasan relevansi, tulisan ini tidak akan menyinggung masa kejayaan Islam di Tanah Rencong tersebut.

Secara keseluruhan, buku ini terdiri dari delapan bab, yang fokus pembahasannya diarahkan pada tiga hal pokok:

Pertama, ilustrasi tentang masa-masa keemasan tradisi keilmuan Islam di wilayah Melayu-Patani, terutama berkaitan dengan peran penting beberapa ulamanya yang disebut di atas. Keberadaan para ulama Melayu-Patani yang - seperti halnya beberapa ulama MelayuIndonesia- memiliki jaringan kuat dengan para ulama Haramayn ini (lihat Azra 1995, khususnya h. 257-266), mampu merintis dan menghidupkan iklim keilmuan Islam di wilayah Melayu-Patani dengan -selain menghasilkan berbagai karya penting di bidang keagamaan-mendirikan lembaga-lembaga pendidikan tradisional, atau yang di Patani dikenal sebagai "pondok". Termasuk dalam bagian pertama ini, pembahasan Madmarn atas signifikasi "Kitab Jawi", yang disebutnya sebagai basic foundation of Islamic knowledge, khususnya dalam konteks dunia Muslim Melayu (h. 49).

Kedua, buku ini melukiskan dilema yang dihadapi oleh komunitas Muslim Melayu-Patani, berkaitan dengan lembaga-lembaga pendidikan tradisional yang diasuhnya, ketika dihadapkan dengan kebijakan pemerintah Thailand, yang memberlakukan nasionalisasi sistem pendidikan di seluruh wilayah, termasuk Patani. Kebijakan ini menghendaki agar seluruh lembaga pendidikan di wilayah Thailand, tidak terkecuali pondok, menerapkan metode belajar-mengajar modern, dan memasukkan materi-materi pelajaran tentang bahasa, agama, dan tradisi budaya Thai yang Budhis. Bagi sebagian besar Muslim Melayu-Patani, yang merupakan kelompok minoritas di Thailand, nasionalisasi sistem pendidikan ini di satu sisi dianggap akan mengganggu -langsung atau tidak - esensi dan keberadaan dari pendidikan Islam tradisional di pondok, dan lebih penting dari itu dianggap akan mengusik identitas etnis, budaya dan agama mereka. Akan tetapi di sisi lain, jika mereka menentang arus, juga bukan jaminan sistem pendidikan tradisional di pondok akan tetap survive, padahal, pada saat yang sama mereka menganggap pendidikan tradisional tersebut sebagai bagian dari identitas yang mereka rumuskan, dan harus dipertahankan.

Ketiga, akhirnya buku ini melukiskan upaya-upaya kelompok 
Muslim Melayu-Patani untuk mengakali kebijakan nasionalisasi sistem pendidikan pemerintah Thailand tersebut, agar di satu sisi bisa safe, tidak bersikap konfrontatif terhadap pemerintah, yang memang dianggap tidak akan menguntungkan, dan di sisi lain bisa tetap mempertahankan nilai-nilai pendidikan Islam tradisionalnya yang biasa diajarkan di pondok. Seperti akan dikemukakan di bawah, salah satu alternatif yang ditempuh oleh para ulama tradisional di pondok adalah dengan terlebih dahulu mengubah institusi pondok, yang dianggap oleh pemerintah sebagai tidak bermutu dan ketinggalan zaman, menjadi Madrasah dengan sistem pendidikan modern, yang secara kurikulum berkiblat ke madrasah-madrasah di Timur Tengah. Pada tahap berikutnya, setelah sistem pendidikan madrasah dianggap feels at home dengan metode belajar-mengajar modern, institusi madrasah ini, kendati tidak semuanya, melakukan berbagai penyesuaian dengan kebijakan pemerintah tentang sistem pendidikan, dengan mengubahnya menjadi sekolah Islam swasta, yang mulai memasukkan beberapa komponen pendidikan budaya Thai. Dengan demikian seperti akan kita lihat dalam pembahasan berikut- alih-alih kehilangan identitas etnis dan agamanya, masyarakat Muslim Melayu-Patani justru memperoleh keuntungan ganda; di satu sisi mereka tetap bisa mempertahankan budaya Melayunya, dan mempelajari budaya dan bahasa Arab, sementara di sisi lain, mereka juga kemudian menguasai budaya Thai, yang menjadi salah satu materi pokok di berbagai sekolah Islam swasta tersebut.

\section{Latar Belakang Historis}

Pembahasan mengenai sejarah Islam di dunia Melayu secara keseluruhan, tampaknya memang tidak mungkin dilakukan tanpa menyertakan wilayah Patani sebagai salah satu topik di dalamnya. Secara historis, wilayah Patani - seperti dikemukakan Madmarn dalam buku ini (h. 11-16) - sejak awal telah memiliki keterkaitan dengan dunia Melayu, baik dalam bidang sosial, politik, perdagangan, maupun budaya. Patani, yang secara geografis terletak di pesisir Timur wilayah Thailand Selatan ini, sebelumnya pernah menjadi salah satu pusat kerajaan Melayu, dan hingga kini, sisa-sisa kejayaannya tersebut masih tampak, terutama karena komunitas Muslim Melayu di Patani masih menggunakan bahasa Melayu dalam kehidupan seharihari mereka. Penggunaan bahasa Melayu ini tampaknya bukan karena mereka tidak menguasai bahasa Thai, tetapi lebih merupakan upaya perumusan identitas etnis dan agama, karena bagi mereka, bahasa 
Melayu tidak sekedar berfungsi sebagai bahasa ibu (mother tongue) belaka, lebih dari itu, bahasa Melayu adalah juga identitas keberagamaan. Dalam hal ini, menjadi Melayu berarti menjadi seorang Muslim, karena bahasa Melayu sangat erat terkait dengan Islam dan berbagai warisan budayanya, seperti akan terlihat dalam pembahasan tentang literatur Kitab Jawi di bawah. Inilah, antara lain, yang membedakan secara mencolok Muslim Melayu-Patani dengan komunitas Thai lainnya, baik dalam hal bahasa, adat istiadat, agama, maupun pola pikir mereka.

Kini, Patani merupakan salah satu dari empat provinsi paling selatan di Thailand selain Yala, Narathiwat, dan Satun. Sejak awal, keempat provinsi ini memang merupakan basis penting komunitas Melayu yang hampir seluruhnya beragama Islam. Khusus mengenai Patani, wilayah ini - seperti telah diisyaratkan di atas- pada paruh pertama abad ke-19 telah menjadi pusat pendidikan Islam tradisional, di mana masyarakat Muslimnya memperoleh pendidikan dasar keislaman sebelum mereka melanjutkan menimba ilmu di lembagalembaga pendidikan di Timur Tengah, khususnya di Haramayn: Makkah dan Madinah. Patani, dalam konteks pendidikan ini, memiliki budaya dan karakter yang unik, baik yang berkaitan dengan masyarakat maupun institusinya. Seperti halnya di wilayah MelayuNusantara lain, semisal Indonesia, Patani melahirkan banyak institusi pendidikan tradisional yang disebut pondok, dengan "tok guru" (Jawa: Kyai) sebagai pemimpin spiritualnya. Melalui insitusi pondok ini, Patani berhasil menarik perhatian kelompok Muslim di wilayah lain untuk datang dan belajar agama di sana. ${ }^{9}$

Akhirnya, melalui proses belajar-mengajar di pondok yang berlangsung secara simultan inilah, Patani kemudian menjadi salah satu early center of Islam, atau, seperti telah dikemukakan, sebagai the cradle of Islam in Southeast Asia (h. 12). Kita bisa menyebut sejumlah pondok yang beberapa di antaranya masih dapat dijumpai hingga kini, yakni Pondok Dalo, Pondok Semla, Pondok Bermin, Pondok Mango, dan beberapa pondok lain yang namanya selalu dihubungkan dengan tok gurunya masing-masing.

\section{Tradisi Intelektual Muslim Melayu-Patani: Sebuah Masa Keemasan}

Munculnya tradisi keilmuan Islam di wilayah Melayu-Patani, tampaknya memang sangat dipengaruhi oleh keberadaan lembaga pendidikan tradisionalnya, pondok. Sejak kemunculannya, institusi pon- 
dok telah mengajarkan dasar-dasar pendidikan Islam tradisional kepada masyarakat Muslim Melayu, bahkan bukan hanya kepada mereka yang tinggal di Patani, tetapi lebih dari itu mereka yang tinggal di Thailand secara keseluruhan. Dengan demikian, pondok telah memainkan peran yang signifikan dalam transmisi keilmuan Islam tradisional di salah satu wilayah dunia Muslim Melayu ini, bahkan hingga paruh pertama abad ke-20 (lihat "The Pondok and its Contribution" dalam bab 2, h. 17-32 buku ini).

Madmarn, dalam buku ini misalnya, mencontohkan bahwa Chana, sebuah kota di Provinsi Songkla, pada kurun waktu 1930 hingga 1950-an menjadi sangat populer karena komunitas Muslim Melayunya. Kota ini, dengan pondok dan tok gurunya yang dikenal baik, menjadi pusat perhatian generasi muda Muslim, khususnya yang berasal dari Nakorn Si Thammaraj, Trang, Krabi, Pangnga, Surat Thani, Phuket, Patthalung, Chaiya, Songkla sendiri, serta kaum Muslim dari empat provinsi paling selatan yang disebut di atas. Mereka datang ke Chana dengan tujuan untuk mendapatkan pendidikan Islam tradisional di berbagai pondok yang tersebar di kota ini (h. 17).

Dengan iklim keagamaan yang demikian kondusif, maka wacana keagamaan di wilayah ini pun relatif lebih dinamis, termasuk munculnya fenomena perdebatan antara "Kaum Tua", yang bersikap konservatif, dengan "Kaum Muda" yang cenderung lebih reformis dalam menafsirkan berbagai ritual keagamaan, seperti talqîn al-mayyit, Ușallî, dll. Seperti halnya yang terjadi di wilayah Melayu lain, semisal Indonesia, kelompok yang disebut sebagai Kaum Muda ini memiliki karakter sebagai reformis yang menggagas dan menyerukan agar umat Islam menjadikan al-Quran dan Hadis Nabi sebagai titik tolak untuk menilai pemahaman keagamaan, tradisi, dan kebudayaan yang ada.

Penting dicatat, bahwa untuk konteks Muslim Melayu di Thailand, -seperti dilukiskan Madmarn dalam buku ini-gerakan reformasi Islam juga menjadi wahana untuk memperjuangkan posisi sosial yang lebih baik bagi komunitas Muslim sebagai kelompok minoritas, di antara kelompok Buddhis sebagai mayoritas. Gerakan ini terutama dilakukan oleh kelompok Muslim yang disebut sebagai Khana Mai di Bangkok, ibukota Thailand. Kelompok ini identik dengan gerakan Kaum Muda di wilayah Thailand Selatan. Hanya saja, berbeda dengan Kaum Muda yang lebih mengedepankan isu-isu keagamaan, Khana Mai lebih concern dengan isu-isu sosial politik. Ini mereka lakukan berdasar pada asumsi bahwa komunitas Muslim di Thailand relatif terbelakang, baik di bidang sosial, ekonomi maupun 
politik. Mereka, antara lain, menuntut kepada pemerintah Thailand agar menerapkan prinsip-prinsip egaliter kepada semua kelompok, termasuk kelompok Muslim Melayu (h. 19).

Masa keemasan tradisi intelektual Islam di wilayah Melayu-Patani yang paling signifikan tentu saja harus merujuk pada masa di mana para ulama angkatan pertamanya - terutama Shaikh Dâwud al-Fattânî dan Shaikh Aḥmad al-Fattânî- banyak menulis karya-karya keagamaan yang kemudian menjadi rujukan penting, baik bagi komunitas Muslim di Patani sendiri, maupun bagi komunitas Muslim di luar wilayah tersebut. Umumnya, karya-karya ulama Patani ini ditulis dalam bahasa Melayu dengan menggunakan tulisan Jawi, dan oleh karenanya sering disebut sebagai kitab Jawi. ${ }^{10}$

Dalam konteks tradisi keilmuan di kalangan Muslim Melayu-Patani, kitab-kitab Jawi karangan para ulamanya ini merupakan khazanah budaya yang sangat penting, setidaknya karena tiga hal: pertama, kitab-kitab Jawi tersebut merupakan bukti historis adanya tradisi intelektual Islam yang signifikan, dan muncul di sebuah wilayah tempat lahirnya para ulama mumpuni sejak permulaan abad ke-19 hingga awal abad ke-20. Penting karena dalam kenyataannya, kitab-kitab Jawi yang ditulis oleh para ulama Patani tersebut kemudian dipakai oleh Muslim Melayu yang lebih luas, bahkan hingga masa kontemporer ini. Kedua, dalam konteks dunia Islam modern, Patani sering dianggap sebagai salah satu pusat keilmuan Islam. Hal ini, antara lain, merujuk pada keberadaan institusi pondoknya, tempat di mana ilmu pengetahuan keislaman -yang dianggap belum terkontaminasi dan berlandaskan kitab-kitab Jawi tersebut- disampaikan. Dan ketiga, khusus dalam konteks Patani, keberadaan kitab-kitab Jawi ini juga menjadi semacam wahana bagi komunitas Muslim untuk mendefinisikan identitas budaya Melayunya. Karena, seperti telah diisyaratkan di atas, kendati masyarakat Melayu merupakan kelompok mayoritas di empat provinsi bagian Selatan Thailand, akan tetapi secara umum di Thailand, mereka merupakan kelompok minoritas. Sehingga, bagi mereka, identitas etnis, agama dan budaya merupakan hal yang sangat penting untuk dimunculkan (lihat Matheson \& Hooker 1988: 4).

Penting juga dicatat bahwa kitab-kitab Jawi yang diakses oleh masyarakat Muslim Melayu-Patani ini tidak terbatas pada kitab-kitab karangan para ulama Patani saja, melainkan juga beberapa kitab Jawi karangan para ulama Melayu-Nusantara lainnya termasuk para ulama Melayu-Indonesia. Madmarn, misalnya, dalam buku ini menye- 
butkan beberapa kitab Jawi karangan ulama Indonesia yang paling populer dan menjadi rujukan penting di Patani, seperti: Sabîl al-Muhtadîn li al-Tafaqquh fî Amr al-Dîn, karangan Shaikh Muhammad Arsyad bin Abd. Allâh al-Banjarî, ulama asal Banjarmasin, Kalimantan Selatan; Sirât al-Hudâ, karangan Shaikh Muhammad Zain al-Dîn bin Muhammad Nadwî al-Sambawî, ulama asal Sumbawa, Nusa Tenggara Barat; Bidâyat al-Hidâyat, karangan Tuan Shaikh Muhammad Zain bin al-Faqîh Jalâl al-Dîn, dari Aceh; dan Kitab Sifat Dua Puluh, karangan Sayyid 'Uthmân bin 'Abd. Allâh bin Yahyâa, dari Betawi. Ini semua menunjukkan betapa hubungan keilmuan di dunia Melayu pada masa-masa tersebut terjalin sedemikian kuat, yang salah satunya melalui pemanfaatan kitab-kitab Jawi.

Lebih dari itu, kitab-kitab Jawi tersebut juga sebenarnya telah menghubungkan dunia Islam Melayu dengan dunia Islam yang lebih luas, mengingat di beberapa wilayah di Timur Tengah sendiri, kitabkitab Jawi mendapat tempat terhormat sebagai bagian dari literatur Islam, di samping tentunya kitab-kitab berbahasa Arab, dan Turki. Ini, misalnya, terlihat dari apresiasi beberapa penerbit yang sangat antusias menerbitkan dan mendistribusikan beberapa karya penting karangan para ulama Melayu, dalam hal ini ulama Melayu-Patani. Jangan lupa, melalui peran penting penerbit inilah, literatur Islam Jawi menjadi lebih tersebar dan tersosialisasi, sehingga kontinuitas tradisi keilmuan Islam tradisional tetap terjaga (h. 54).

Madmarn dalam buku ini juga melukiskan bahwa dalam konteks Melayu-Patani, -dan sebetulnya juga di dunia Melayu pada umumnya- kitab-kitab Jawi tersebut sebagian besar ditulis oleh para ulamanya untuk memenuhi kebutuhan masyarakat Muslim Melayu yang ingin mempelajari pengetahuan Islam tradisional, tetapi tidak memahami bahasa Arab. Ini menunjukkan satu sikap responsif dari para ulama tersebut atas permintaan dari murid-murid Melayunya, yang juga berarti menunjukkan betapa para ulama Patani tersebut telah memainkan peranan penting dalam transmisi keilmuan kepada masyarakat Muslim di dunia Melayu (h. 49).

Menarik juga dikemukakan bahwa hingga paruh kedua abad ke20, aktifitas keagamaan para ulama Melayu-Patani ini, terutama dalam hal transmisi keilmuan, tidak menjadi surut kendati dalam tingkat progresifitas yang berbeda. Salah satu bentuk transmisi keilmuan yang masih berkesinambungan adalah proses belajar mengajar di Masjidil Haram. Madmarn mencontohkan bahwa pada kurun 1920 hingga sekitar 1950-an, setidaknya ada tiga ulama besar Melayu-Patani yang 
menjadi guru di Masjidil Haram, yaitu: Shaikh 'Abd. Al-Qâdir bin 'Abd. Al-Mutallib al-Mandilî, yang sebenarnya berasal dari Mandailing, Sumatra Utara, Haji Ismail bin 'Abd. al-Qâdir, yang lebih dikenal sebagai Pak Do'Ae, dan Haji Ismail bin Haji Wan Ahmad, atau Tok Semla Tua (h. 34). Dan yang paling mutakhir diketahui sebagai shaikh di Masjidil Haram adalah Haji Husain Surat (Kru Sen), dan Haji Ali (Kru Li).

\section{Antara Nasionalisme dan Identitas Budaya}

Bahwa sebuah pemerintahan mengeluarkan kebijakan untuk mengatur sistem pendidikan di negaranya, sebenarnya merupakan suatu hal yang wajar. Apalagi jika kebijakan tersebut didasarkan pada alasan-alasan yang rasional, seperti -dalam konteks kehidupan bernega$\mathrm{ra}$ - untuk mempersatukan kepentingan setiap kelompok agama dan etnis yang ada. Akan tetapi tidak sesederhana itu dengan apa yang terjadi di Patani. Ketika pada 1970, pemerintah Thailand mengeluarkan kebijakan untuk memberlakukan nasionalisasi sistem pendidikan di seluruh wilayah, termasuk mengganti sistem pendidikan tradisional yang berlaku di pondok-pondok di Melayu-Patani, para elit Muslimnya mengajukan keberatan. Mereka menentang usahausaha pemerintah untuk memberlakukan sistem pendidikan modern di wilayahnya. Lebih jauh mereka bahkan menganggap bahwa kebijakan tersebut merupakan bagian dari upaya pemerintah Thai untuk menghegemoni, dan bahkan mengganti kultur mereka, yang Melayu dan Islam dengan kultur Thai yang Budhis (lihat Dulyakasem 1989: 256).

Resistensi dari kelompok Muslim Melayu ini tampaknya harus dipahami sebagai bagian kecil saja dari ketegangan dan tarik menarik yang telah lama terjadi antara Pemerintah Thailand dengan kelompok minoritas Muslim Melayu. ${ }^{11}$ Dalam hal ini, pihak Pemerintah Thai telah lama ingin "mengajak" Muslim Melayu di empat Provinsi yang menjadi basis komunitasnya, khususnya di Patani, untuk "menjadi orang Thai", dengan segala atribut dan identitasnya (h. 73). Upaya pemerintah ini diwujudkan melalui beberapa bentuk, seperti sekularisasi pendidikan di pondok-pondok, penyebaran dan sosialisasi bahasa Thai, pengurangan penggunaan bahasa Melayu, dll. Ini-dalam kaca mata pemerintah- dilakukan, antara lain dengan pertimbangan bahwa perbedaan bahasa dan budaya sangat memperlambat dan bahkan menghambat interaksi dan sosialisasi program program pemerintah di kalangan Melayu Muslim, yang nota bene juga warga 
negara Thai. Khusus dalam hal pondok, pemerintah Thai tampaknya memang merasa khawatir lembaga tersebut akan menjadi semacam lembaga politis yang diorientasikan untuk memperkuat loyalitas etnis (Melayu). Selain itu pemerintah menganggap bahwa sistem pendidikan di pondok tidak memenuhi standar modern, dan pendidikan yang diberikannya "bermutu rendah". Tidak heran, jika kebijakan pemerintah di bidang pendidikan ini banyak juga diarahkan untuk "mendesak" pendidikan pondok untuk diubah menjadi semacam "Sekolah Islam Swasta yang mengajarkan Islam" saja (lihat Du.yakasem 1989: 265).

Hanya saja di sisi lain, "ajakan" pemerintah itu mendapat reaksi negatif dari kelompok Muslim Melayu, karena hal tersebut - setidaknya menurut mereka- membawa konsekuensi pada menipis, dan bahkan musnahnya, identitas mereka dalam hal bahasa, adat istiadat, budaya, dan terutama kekhasan sistem pendidikannya (h. 74). Mereka khawatir kebijakan pemerintah tersebut akan mengantar masyarakat Muslim Melayu masuk pada kebudayaan yang tidak diinginkannya. Melalui pengenalan bahasa Thai misalnya, kalangan Muslim MelayuPatani merasa khawatir bahasa tersebut pada akhirnya akan menggeser fungsi bahasa Melayu dan Arab, baik di tingkat institusi pendidikannya, maupun dalam kehidupan sehari-hari, apalagi jauh-jauh hari mereka telah "memasang" asumsi bahwa melalui kebijakan tersebut, pemerintah Thai berusaha mematikan bahasa Melayu, dan memarjinalkan generasi Muda Melayunya (lihat Dulyakasem 1989: 256).

Bagi golongan Muslim Melayu, semua perkembangan ini dianggapnya sebagai suatu usaha pemerintah yang tidak beralasan dan tidak bisa dibenarkan untuk menyingkirkan mereka secara kultural. Alhasil, kaum Muslim Melayu merasa bahwa bahasa, agama, dan semua tradisi budaya mereka sedang berada dalam bahaya. Reaksi-reaksi mereka terhadap hal ini semua, lebih jauh menyuburkan perasaan solidaritas etnis dalam menghadapi ancaman dari luar.

Apalagi dalam kaitannya dengan institusi pondok, yang sejak awal telah menjadi simbol ke-Islam-an dan ke-Melayu-an, dan bahkan telah menjadi semacam tempat perlindungan budaya golongan Muslim Melayu, para elit Muslim Melayu merasa khawatir pada akhirnya kebijakan pemerintah yang berkaitan dengan pendidikan tersebut akan secara perlahan meminggirkan keberadaan dan peranannya yang sejauh ini sudah dianggap berhasil dalam proses transmisi keilmuan Islam tradisional, dan transformasi sosial masyarakatnya.

Kekhawatiran masyarakat Muslim Melayu-Patani ini tampaknya 
tidak terlalu berlebihan, mengingat sistem pendidikan umumnya diyakini memiliki satu peranan penting, sosialisasi. Sistem pendidikan akan membantu mensosialisasikan pesan-pesan kebudayaan, nilainilai, dan ideologi-ideologi tertentu, sehingga setiap orang yang terlibat di dalamnya akan terpengaruh oleh pesan-pesan yang dibawanya tersebut. Selain itu, masyarakat Melayu-Muslim Patani tampaknya juga khawatir akan munculnya tantangan terhadap legitimasi sistem pendidikan tradisional yang sejauh ini telah berhasil menghasilkan elit-elit lokal. Dengan berbagai kekhawatiran tersebut, wajar jika kemudian mereka memobilisasi dan mengorganisasi anggota kelompok etnisnya untuk semaksimal mungkin membendung usaha pemerintah Thai untuk menghegemoni sistem pendidikan tradisional di pondok (tentang hal ini, lihat juga Dulyakasem 1989: 242-244).

\section{Madrasah: Sebuah Solusi}

Dari pembahasan Madmarn dalam buku ini, tampak bahwa kuatnya desakan pemerintah untuk menerapkan sistem pendidikan modern, mempunyai berbagai dampak politis, kebudayaan, dan bahkan ekonomis bagi kelompok Melayu Muslimnya, karena -dalam konteks wilayah ini- modernisasi sistem pendidikan tersebut telah berfungsi tidak hanya untuk menyebarkan kebudayaan dan ideologi nasional (Thai) kepada masyarakat Muslim Melayu, tetapi juga mengecilkan - baik secara sosial maupun ekonomis- status pendidikan tradisionalnya, dalam hal ini pondok.

Kendati demikian, kelompok Muslim Melayu tersebut tampaknya menyadari bahwa bersikap a-priori menolak saja niscaya tidak akan menyelesaikan masalah; yang harus dilakukan adalah mencari solusi agar di satu sisi kultur Melayu dan warisan Islam tradisional mereka tetap terpelihara, dan pada saat yang sama mereka juga bisa memenuhi harapan pemerintah dalam hal modernisasi sistem pendidikan, serta, tentunya sebagai warga negara, berintegrasi dengan kelompok etnis lainnya.

Inilah, antara lain, latar belakang yang kemudian mengilhami para pemuka Muslim Melayu di Patani untuk mencari jalan tengah yang menguntungkan seperti diisyaratkan di bagian awal tulisan ini. Dan di antara pilihan yang diambil adalah dengan melakukan transformasi institusi pondok menjadi apa yang kini dikenal sebagai "Madrasah". Institusi madrasah -yang diharapkan dapat menjembatani keinginan pemerintah Thai untuk menerapkan sistem pendidikan modernsejauh itu memang dianggap sebagai jalan keluar terbaik, karena di 
satu sisi masih membuka kemungkinan tetap dipertahankannya nilai nilai tradisional yang terdapat di pondok, dan pada saat yang sama dapat menerapkan sistem pendidikan modern, dengan berkiblat ke sistem madrasah di beberapa negara Muslim, khususnya di Timur Tengah yang sudah dianggap modern (h. 80).

Meskipun terdapat perbedaan dalam beberapa hal, tampaknya fenomena perubahan pondok menjadi madrasah di Patani ini paralel dengan fenomena pesantren yang ada di wilayah Melayu-Indonesia, khususnya Jawa. Seperti diketahui, eksistensi pesantren di Jawa sejak akhir abad ke-19 mendapat tekanan akibat kebijakan politik pemerintah kolonial Belanda yang berniat memperluas pengaruh kolonialnya, dan ingin meredam pengaruh pesantren yang terlanjur besar. Belanda, dalam hal ini ingin "menandingi" pesantren dengan memperkenalkan jenis sekolah yang mengajarkan berbagai ilmu pengetahuan umum, dan sistem pendidikan Barat. Sebagai jawaban atas tantangan tersebut, para kyai kemudian memperkenalkan sistem madrasah, dengan mengajarkan pengetahuan umum dalam lingkungan pesantren, sehingga pada akhirnya pesantren tetap mampu mengkonsolidasikan keberadaannya sebagai transmitter keilmuan Islam tradisional. Memang, di Jawa sendiri, tidak semua pesantren mengalami pola perubahan yang sama. Dhofier (1994), misalnya, mengelompokkan 2 kecenderungan pesantren setelah didera arus modernisasi: pertama, apa yang disebut sebagai pesantren salafi. Tipe pesantren ini tetap konsisten dengan pengajaran kitab-kitab Islam klasik, dan tidak terlalu terpengaruh untuk mengajarkan pengetahuan umum bagi para santrinya. Kedua, pesantren khalafi, yang sangat giat mengembangkan model pendidikan madrasah, dengan memasukkan berbagai pengetahuan umum, atau bahkan membuka sekolah-sekolah umum, semisal SMP, SMA, dan universitas di pesantrennya.

Di Patani sendiri, kendati di awal pertumbuhannya menghadapi banyak kendala, pilihan terhadap bentuk madrasah ini tampaknya mulai memperlihatkan hasil yang diharapkan. Secara perlahan, dan tentunya hati-hati, madrasah-madrasah tersebut mulai terbiasa mengadopsi dan menerapkan berbagai kebijakan pemerintah di bidang pendidikan, termasuk memasukkan pendidikan budaya Thai. Bahkan, belakangan madrasah-madrasah ini merubah dirinya menjadi Sekolah Islam Swasta, di mana para pelajarnya mendapat dua jenis pendidikan: pertama, pendidikan Melayu-Islam, yang meliputi pelajaran bahasa Arab, dan kedua pendidikan Thai, yang umumnya meliputi dua bidang studi: pengetahuan umum (sciences), dan seni budaya (arts). 
Dengan demikian, di Patani - menurut pengamatan Madmarnkendati terjadi reformasi dan transformasi sistem pendidikan pondok, hal itu tidak menyebabkan punahnya pendidikan Islam tradisional. Diperkenalkannya pendidikan budaya Thai, karenanya, tidak menimbulkan gangguan terhadap usaha masyarakat Melayu-Muslim dalam memelihara doktrin-doktrin Islam tradisional. Hal ini antara lain tampak dari tetap digunakannya kitab-kitab klasik di berbagai madrasah tersebut, baik dalam bahasa Jawi maupun Arab, yang dikarang oleh para ulama Patani, dan para pengarang Muslim lainnya. Bahkan, alih-alih kehilangan kultur Melayu dan Islamnya, masyarakat Muslim Patani kini mendapat dua keuntungan ganda: mampu mengadopsi sistem pendidikan modern dengan tetap mempertahankan nilai-nilai pendidikan tradisionalnya (h. 75).

Seperti ditunjukkan Madmarn dalam buku ini (h. 83-85), kurikulum madrasah-madrasah yang berkembang di Patani tersebut, sepenuhnya didisain dan diarahkan untuk dapat diterima oleh lembagalembaga pendidikan modern di negara-negara Timur Tengah. Dan dalam kenyataannya, beberapa madrasah yang menerapkan sistem pendidikan modern di Patani khususnya, dan di tiga propinsi lainnya ini, telah mendapatkan pengakuan dan akreditasi dari kementrian pendidikan di Arab Saudi, sehingga hal tersebut memungkinkan para lulusannya untuk melanjutkan pendidikan yang lebih tinggi di negara-negara tersebut.

Di samping itu, beberapa madrasah juga tetap berusaha mengadopsi materi-materi yang ditawarkan pemerintah menyangkut pendidikan budaya Thai. Apalagi, pemerintah mengeluarkan kebijakan untuk memberikan bantuan finansial kepada madrasah-madrasah yang menyertakan pendidikan Thai tersebut, sehingga karena didorong keinginan untuk tetap survive, kebanyakan madrasah mengakomodasi kebijakan pemerintah tersebut, meskipun dengan bobot yang beragam; sebagian menerapkan secara penuh materi-materi yang ditawarkan pemerintah, sebagian lagi hanya menerapkan beberapa saja.

Upaya rekonsiliasi antara Muslim-Melayu di Patani, dan di tiga propinsi lainnya ini, tampaknya semakin terus dikembangkan. Pemerintah Thai sendiri -yang berharap agar reformasi di bidang pendidikan ini berjalan lebih efektif- telah membentuk lembaga semacam "Pusat Pendidikan" di Propinsi Yala, yang bertujuan untuk lebih mensosialisasikan program pendidikan Thai di sekolah-sekolah Islam swasta, atau madrasah. Lebih jauh, lembaga ini bahkan merancang sebuah program kajian Islam (Islamic Studies Program) di beberapa 
sekolah umum milik pemerintah, dengan harapan dapat menarik minat masyarakat Muslim-Melayu untuk juga menyekolahkan anakanaknya di sana. Akan tetapi, program ini tampaknya tidak terlalu memuaskan pihak pemerintah, karena, kendati banyak anak-anak Muslim-Melayu yang mengikuti program pendidikan di sekolahsekolah umum tersebut, kenyataannya, dalam kehidupan sehari-hari mereka tetap lebih cenderung mempraktekkan adat istiadat dan tradisi Melayu-Islamnya, dibanding budaya Thai yang sebenarnya kedua-duanya diajarkan. Madmarn, misalnya, mencontohkan bahwa alih-alih mengikuti tradisi budaya Thai dalam memberikan salam dan menyapa sesamanya, ${ }^{12}$ anak-anak Melayu-Muslim itu tetap mengucapkan "assalâmu'alaikum".

Lepas dari perkembangan yang belum memuaskan tersebut, dalam pembahasan akhir buku ini, Madmarn - berbeda dengan para penulis lain tentang Patani- tampaknya sangat optimistis dengan perkembangan pendidikan Islam di Patani. ${ }^{13}$ Madmarn melihat bahwa kecenderungan pemerintah Thai untuk mengakomodasi aspirasi kalangan Muslim Melayu di bidang pendidikan, juga terlihat pada level perguruan tingginya. Madmarn mencontohkan bahwa di Universitas Prince of Songkla, Thailand, sejak tahun 1982 secara resmi telah dibuka Program Kajian Islam dan Program Bahasa Arab. Tampaknya, selain karena bahasa Arab secara global sudah dianggap sebagai salah satu bahasa komunikasi terpenting, kedua program tersebut diselenggarakan untuk menciptakan iklim yang kondusif berkaitan dengan saling pengertian dan toleransi di antara masyarakat Thailand yang multietnis (h. 109). Tentu saja, yang berhak mengikuti program-program tersebut adalah mereka yang memiliki ijazah formil dari lembaga pendidikan yang diakui pemerintah, semisal Sekolah Umum dan Sekolah Islam Swasta, atau Madrasah.

\section{Catatan Akhir: Kritik dan Apresiasi}

Membaca buku yang sebenarnya tidak terlalu tebal ini, kita akan menjumpai pembahasan menarik yang berbeda dengan beberapa buku tentang Melayu-Patani sebelumnya. Ini karena wilayah pembahasannya yang masih jarang dilakukan oleh para sarjana, yakni tentang tradisi besar keilmuan Islam tradisional. Seperti diketahui, pembahasan atas wilayah Patani kebanyakan lebih terfokus pada separatisme Muslim Patani setelah Perang Dunia II, ${ }^{14}$ sedangkan perhatian atas pertumbuhan tradisi dan lembaga-lembaga Islam di kalangan Muslim Patani pada periode awal, masih jarang dilakukan. 
Kelebihan lain dari buku yang dilengkapi dengan indeks ini adalah dari segi literatur yang digunakannya. Seperti terlihat di bagian bibliografi (h. 129-140), selain buku-buku standar dan hasil wawancara yang dirujuknya, Madmarn juga menyertakan tidak kurang dari 30-an sumber dalam bahasa Thai, yang sesungguhnya tidak mudah diakses oleh sarjana di luar Thai.

Sayangnya, dalam buku ini Madmarn hampir tidak sama sekali mengupas fenomena lembaga-lembaga pendidikan tradisional di wilayah Melayu-Nusantara lain, semisal Indonesia atau Malaysia. Ini -jika dilakukan - sebenarnya bisa lebih memperkaya pembahasan, mengingat dalam konteks lembaga pendidikan tradisional, sesungguhnya banyak hal yang paralel antara fenomena di satu wilayah dengan apa yang terjadi di wilayah lainnya. Di Indonesia misalnya, kendati didasari motivasi yang berbeda, lembaga-lembaga pendidikan tradisionalnya -seperti diisyaratkan dalam pembahasan di atas- juga mengalami semacam tekanan dari pihak luar, dalam hal ini pemerintah kolonial Belanda, untuk mengadopsi sistem pendidikan Barat yang dianggap lebih modern (lihat Dhofier 1994: 38). Sementara contoh Malaysia, pembahasannya akan menarik karena menampilkan fenomena yang lain berkaitan dengan pendidikan Islam tradisionalnya. Seperti diketahui, pondok di Malaysia merupakan salah satu contoh lembaga pendidikan Islam tradisional, yang nasibnya "lebih buruk" dibanding dengan yang terjadi di dunia Melayu lainnya; karena lebih bersifat defensif, dan kurang bisa menyesuaikan diri dengan arus sistem pendidikan modern, sehingga eksistensinya semakin terancam (tentang hal ini lihat Abu Bakar 1995: 1164-1195; lihat juga Steenbrink 1994: xiv).

Akhirnya, sebagai khazanah keilmuan, buku ini sangat layak untuk dibaca, apalagi sejauh ini pembahasan tentang Islam di Patani masih terasa belum maksimal, dan "belum ada apa-apanya" dibanding kejayaan tradisi intelektual Islam yang pernah diraihnya. 


\section{Catatan}

1. Pembahasan lebih jauh mengenai semua istilah yang mengacu pada lembaga pendidikan tradisional di berbagai wilayah Nusantara ini, lihat Azra 1988, terutama h. 19-21.

2. Lihat Matheson \& Hooker 1988: 4; lebih lanjut tentang "Idiom, Identity and Legitimation", lihat juga Roy F. Ellen dalam Hooker (ed.) 1983: 71-78.

3. Untuk kasus Melayu-Indonesia, arus modernisasi di bidang pendidikan tersebut terutama seiring dengan berbagai kebijakan politik pemerintah kolonial Belanda sejak akhir abad ke-19. Lain halnya dengan yang terjadi di wilayah MelayuPatani, arus modernisasi tersebut - seperti akan dibahas di bawah-disebabkan oleh tarik menarik kepentingan antara masyarakat Melayu-Muslimnya dengan pihak pemerintah, dalam hal ini pemerintah Thai.

4. Malaysia, merupakan salah satu contoh wilayah dunia Melayu yang sebagian besar lembaga-lembaga pendidikan tradisionalnya tidak mampu bertahan atas "gempuran" ekspansi sistem pendidikan modern (lihat Steenbrink 1994: xiv-xv). Sementara Indonesia, dan juga Patani yang menjadi pembahasan utama buku ini, merupakan contoh wilayah, yang lembaga-lembaga pendidikan tradisionalnya relatif mampu beradaptasi dengan perkembangan sistem pendidikan modern, kendati untuk wilayah yang disebut kedua - seperti akan dibahas di bawahproses transformasinya mengalami perjuangan yang relatif lebih sulit.

5. Tanggal lahir dan wafat Shaikh Dâwud al-Fattânî belum dapat dipastikan. Ada beberapa kemungkinan, yaitu tahun 1133/1720,1153/1740, dan 1183/1769 (lihat Abdullah 1990: 23). Shagir Abdullah -yang konon merupakan keturunan langsung dari Shaikh Dâwud al-Fattânî- belakangan lebih memilih tahun 1133/ 1720 , terutama setelah ia menjumpai tulisan Tuan Guru Haji 'Abdul Hâmid bin "Abdul Qâdir as-Sanawai yang menjelaskan bahwa: "Dan sangat mustajab doanya dan panjang umurnya kadar 166 tahun. Iaitu mati pada masa Sultan Syarif Muhammad Arsyad Khan al-'Abbasi 1297 H'. Abdullah kemudian menghitung mundur usia 166 tahun Shaikh Dâwud al-Fattânî dari tahun $1297 \mathrm{H}$ tersebut, yang hasilnya adalah $1131 \mathrm{H}$. kendati selisih 2 tahun dengan 1133 yang banyak diperbincangkan, menurut Abdullah, angka tersebut adalah yang paling mungkin (lihat Abdullah 2000: 2-3).

6. Berbeda dengan Shaikh Dâwud al-Fattânî, biografi Shaikh Ahmad al-Fattânî relatif lebih jelas. Ia hidup dan berkarir antara 1856 hingga 1906. Lebih detil tentang riwayat hidup dan karya-karyanya, lihat, antara lain, Matheson \& Hooker 1988: 28-30.

7. Azra, seraya mengutip Abdullah 1990 dan Matheson \& Hooker 1988, menyebut angka 57 untuk karya-karya Shaikh Dâwud al-Fattânî (Azra 1995: 266). Akan tetapi, berdasarkan penelitian paling mutakhir yang dilakukan oleh Shagir Abdullah, karya al-Fattânî mencapai jumlah 66 buah, yang beberapa manuskrip di antaranya baru diketahui pada tahun 1995 melalui tulisan seorang ulama Patani, yaitu Tok Kelaba al-Fattani (lihat Abdullah 2000: 13-27).

8. Tentang hal ini, lihat Azra 1995, terutama bab IV, h. 166-211.

9. Menjelang akhir abad ke-19, dan awal abad ke-20, masyarakat Muslim dari bagian utara tanah Melayu, semisal Kelantan, Kedah dan Perlis biasa datang ke Patani untuk memperdalam ilmunya (lihat Salleh 1984: xxiii; lihat juga Dulyakasem 1989: 299).

10. Ada beberapa asumsi tentang asal muasal penamaan kata "Jawi" ini. Omar Awang 
misalnya menduga bahwa kata Jawi mungkin berasal dari kata Arab "al-jâwaah" yang pernah digunakan dalam beberapa catatan orang Arab, semisal Ibnu Batutah, dalam Riḥlat Ibnu Battûtah, sebelum pertengahan abad ke-14 untuk menamakan pulau Sumatra. Oleh karenanya, menurut Omar Awang, bisa jadi kata Jawi itu merupakan nama yang diberikan oleh orang Arab untuk merujuk tulisan yang digunakan oleh orang Sumatra yang beragama Islam dan berbahasa Melayu (Omar Awang dalam Musa 1997: 69-70, dan 1999: 9). Selain itu, W. Marsden - dengan mengutip Raffles- juga pernah menengarai bahwa kata Jawi dapat dinisbahkan kepada orang Melayu, yang berarti campuran (mixed, crossed). Dalam hal ini, kata Jawi berarti campuran antara tulisan Melayu dan Arab (lihat Marsden dalam Musa 1997: 70, dan 1999: 9).

11. Tentang ketegangan dimaksud, lihat, antara lain, Dulyakasem, "Kemunculan dan Perkembangan Nasionalisme Etnis; Kasus Muslim di Siam Selatan", dalam Abdullah \& Siddique (ed.) 1989: 239-296; lihat juga Farouk, "Asal-usul dan Evolusi Nasionalisme Etnis Muslim Melayu di Muangthai Selatan" dalam Abdullah \& Siddique (eds.) 1989: 297-340.

12. Budaya Thai mengajarkan bahwa untuk memberikan salam kepada orang lain, seseorang harus mengangkat seraya merapatkan kedua telapak tangannya ke dada, dan sedikit membungkukkan kepala.

13. Umumnya, para sarjana yang menulis tentang Patani, cenderung bersikap pesimis dengan perkembangan pendidikan Islam di Patani, lihat misalnya Hassan 1989: 415 .

14. Di antara tulisan dengan kecenderungan seperti ini adalah Haemindra, 19761977; Dulyakasem 1989: 239-296; Omar Farouk 1989: 297-340; dan yang paling mutakhir, antara lain, Mahmud 1999. 


\section{Bibliografi}

Abdullah, H. W. M. Shagir. 1990. Syeikh Daud bin Abdullah Al-Fatani: Ulama dan Pengarang Terulung Asia Tenggara. Kuala Lumpur: Hizbi.

2000. Penyebaran Islam dan Silsilab Ulama Sejagat Dunia Melayu Jilid 10.

Pengenalan Siri Ke-11 [seri ini telah terbit hingga nomor ke-11]. Kuala Lumpur: Persatuan Pengkajian Khazanah Klasik Nusantara \& Khazanah Fathaniyah.

Abdullah, Taufik \& Sharon Siddique (ed.). 1989. Tradisi dan Kebangkitan Islam di Asia Tenggara. Jakarta: LP3ES.

Abu Bakar, Mohamad. 1995. "Dari Pusat ke Pinggiran: Institusi Pondok di Malaysia" dalam Ismail Hussein dkk. Tamadun Melayu. Kuala Lumpur: Dewan Bahasa dan Pustaka, jilid 3.

Azra, Azyumardi. 1988. "The Rise and Decline of the Minangkabau Surau". Tesis MA. Columbia University, tidak terbit.

1995. Jaringan Ulama Asia Tenggara: Timur Tengab dan Kepulauan Nusantara Abad XVII dan XXVIII. Bandung: Mizan, cetakan kedua.

Deutch, K. W.. 1969. Nationalism and its Alternatives. New York: Koft.

Dhofier, Zamakhsyari. 1994. Tradisi Pesantren: Studi tentang Pandangan Hidup Kyai. Jakarta: LP3ES. cetakan keenam.

Dulyakasem,Uthai. 1989. "Kemunculan dan Perkembangan Nasionalisme Etnis: Kasus Muslim di Siam Selatan” dalam Abdullah, Taufik \& Sharon Siddique (ed.).

Ellen, Roy F., "Social Theory, Ethnography and the Understanding of Practical Islam in South-East Asia" dalam Hooker (ed.), 1983.

Farouk, Omar. 1989. “Asal-usul dan Evolusi Nasionalisme Etnis Muslim Melayu di Muangthai Selatan" dalam Abdullah, Taufik \& Sharon Siddique (ed.).

Geertz, Clifford. 1976. The Religion of Java. Chicago \& London: University of Chicago Press.

Haemindra, Nantawan. 1976-1977. "The Problem of Thai Muslims in the Four Southern Provinces of Thailand" dalam Journal of Southeast Asian Studies, bagian 1 dan 2.

Hassan, M. Kamal. 1989. "Beberapa Dimensi Pendidikan Islam di Asia Tenggara" dalam Abdullah, Taufik \& Sharon Siddique (ed.).

Hooker, M. B. (ed.). 1983. Islam in South-east Asia, Leiden: E. J. Brill.

Mahmud, Nik Anuar. 1999. Sejarah Perjuangan Melayu Patani 1785-1954. Bangi: Penerbit Universiti Kebangsaan Malaysia.

Matheson, Virginia \& M. B. Hooker. 1988. "Jawi Literature in Patani: The Maintenance of an Islamic Tradition" dalam JMBRAS, vol. LXI, part. 1.

Musa, Hashim Haji. 1997. Epigrafi Melayu: Sejarah Sistem Tulisan dalam Bahasa Melayu. [Siri Monograf Sejarah Bahasa Melayu]. Kuala Lumpur: Dewan Bahasa dan Pustaka.

1999. Sejarah Perkembangan Tulisan Jawi, Kuala Lumpur: Dewan Bahasa dan Pustaka.

Muzani, Saiful (ed.). 1993. Pembangunan dan Kebangkitan Islam di Asia Tenggara. Jakarta: LP3ES.

Rahardjo, Dawam. 1974. Pesantren dan Pembaharuan. Jakarta: LP3ES.

Salleh, Bariyyah Haji. 1984. Kampung Haji Salleh dan Madrasah Saadiah-Salibiab 1914. 1959. [siri kajian sejarah setempat]. Kuala Lumpur: Dewan Bahasa dan Pustaka.

Steenbrink, Karel A.. 1994. Pesantren, Madrasah, Sekolab; Pendidikan Islam dalam Kurun Moderen. Jakarta: LP3ES. cetakan kedua. 
Suryo, Djoko. 2000. "Tradisi Santri dalam Historiografi Jawa: Pengaruh Islam di Jawa", makalah dalam "Seminar Sehari Pengaruh Islam terhadap Budaya Jawa dan Sebaliknya", kerja sama Perpusnas RI dengan University of Melbourne, Jakarta, 31 Oktober 2000.

Oman Fathurahman, Staf Pengajar di Fakultas Adab IAIN Syarif Hi. dayatullah Jakarta. 